\title{
DESIGN AND CONSTRUCTION OF THE BOSCOMBE MULTI-PURPOSE REEF
}

\author{
Shaw T. Mead ${ }^{1}$, Chris Blenkinsopp ${ }^{2}$, Andrew Moores ${ }^{1}$, and Jose Borrero ${ }^{1}$
}

\begin{abstract}
The Boscombe Reef is a multipurpose reef structure designed primarily for the enhancement of surfing amenity at Boscombe, Poole Bay, England. The reef was designed to maximise the small and generally poor-quality surfing wave climate of the eastern English Channel coast. The reef was constructed from 54 large, sand filled geotextile containers ranging in size from 1 to $5 \mathrm{~m}$ diameters and 15 to $70 \mathrm{~m}$ long with a total volume of approximately 13,000 $\mathrm{m}^{3}$. Construction of the reef began in the summer of 2008, was suspended during the following winter and was completed in the late summer of 2009 . The reef is now in service and provides a high intensity right hand surfing ride of up to $70 \mathrm{~m}$ and a shorter left hand ride of up to $30 \mathrm{~m}$. Although the reef was not designed as a coastal protection structure, monitoring of the morphological response supports that the reef promotes shore protection through the formation of an inshore salient.
\end{abstract}

Keywords: artificial reef; submerged breakwater; surfing; recreation; shore protection; salient formation

\section{INTRODUCTION}

The Bournemouth Borough Council commissioned ASR Ltd to develop a multi-purpose reef for recreational purposes in Boscombe. The reef is part of a municipal redevelopment scheme, the Boscombe Spa, which included the refurbishment of the local pier as well as the development of restaurants, shops and residential property. The aim of the reef project was to enhance surfing at a site which presently provides only mediocre surfing conditions. While designed primarily for surfing, the coastal protection aspects of these structures is also of interest.

\section{NEARSHORE ENVIRONMENT AND DESIGN CRITERIA}

Boscombe is located in the western English Channel on the south coast of England, approximately $150 \mathrm{~km}$, southwest of London. Due to its location, Boscombe is sheltered from the large swells of the north Atlantic Ocean. Frequently however, local winds produce short choppy seas affecting the area. Despite the adverse conditions for recreational wave riding, surfing is nevertheless a popular activity here, with the third largest surfing population in the UK.

Since multi-purpose reef design projects are limited by physical and economic constraints, the design must take into account a wide range of factors to obtain the optimum solution for a particular location. At Boscombe, the key factors investigated as part of the iterative reef design process were the wave climate, the wind climate and the crest height.

For the design process, detailed field studies were conducted at the proposed reef site. This included surveys to accurately represent the nearshore bathymetry. Wave data was collected from both a waverider directional buoy located $1 \mathrm{~km}$ offshore of the Boscombe Pier (Figure 1a) and supplemented with a 6 week deployment of an in-situ wave and current meter in $5 \mathrm{~m}$ water depth at the proposed reef site. Wave transformation studies were conducted between the two data sets to establish an inshore wave climate for the design process. The design wave conditions for the reef were for $H_{10}=1 \mathrm{~m} \pm 0.5$ $\mathrm{m} ; T=7 \mathrm{~s} \pm 2 \mathrm{~s}$, and wave direction coming from $191^{\circ} \mathrm{N} \pm 6^{\circ}$.

Water level information was derived from a tide gauge located on the Bournemouth Pier. The tidal range between MHWS and MLWS at Bournmouth is $1.76 \mathrm{~m}$. The tidal signal at Boscombe is asymmetrical in nature with a prolonged double-peak high water period and a short sharp change in water levels at low tide (Figure 1b). This asymmetric tidal curve means that water levels are above mid-tide level for $75 \%$ of the time and had significant impact on the reef design. To ensure that waves break on the reef for a reasonable proportion of the tidal cycle it was necessary to raise the crest to a level above mean low water springs.

\footnotetext{
${ }^{1}$ ASR Limited, Marine Consulting and Research, 1 Wainui Road, Raglan, 3297, New Zealand

${ }^{2}$ Water Research Laboratory, University of New South Wales.
} 

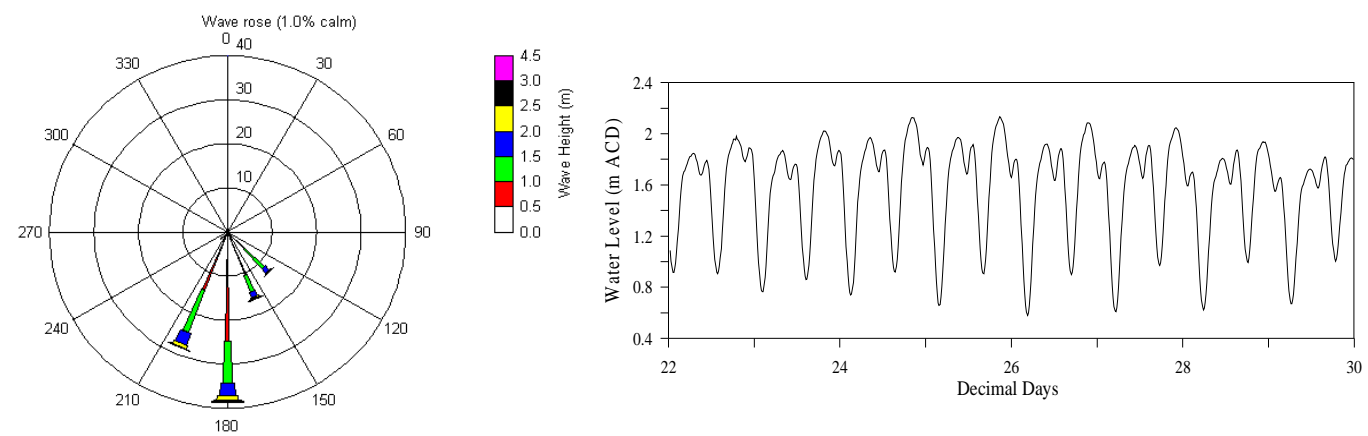

Figure 1. (a) A rose plot for the Boscombe wave climate showing waves coming from predominantly a southerly and south-southeasterly wave direction. (b) A time series of the highly asymmetrical tide signal at the reef site.

\begin{tabular}{|l|c|}
\hline $\begin{array}{l}\text { Table 1. } \\
\text { at Boscombe. }\end{array}$ \\
\hline Tide Level & $\begin{array}{c}\text { Water Level } \\
(\mathrm{m}, \mathrm{ACD})\end{array}$ \\
\hline HAT & 2.59 \\
\hline MHWS & 2.21 \\
\hline MHWN & 1.67 \\
\hline MLWN & 1.17 \\
\hline MLWS & 0.45 \\
\hline LAT & -0.06 \\
\hline
\end{tabular}

A wind rose for the site is shown in Figure 2. The data suggests that southwesterly winds are most common, however the wind can come from virtually any direction. The wind climate can be severe with winds frequently exceeding $10 \mathrm{~m} / \mathrm{s}$ (19.4 knots). Indeed, local surfers report that surfing conditions are frequently driven by or in conjunction with strong local winds - a less than ideal situation

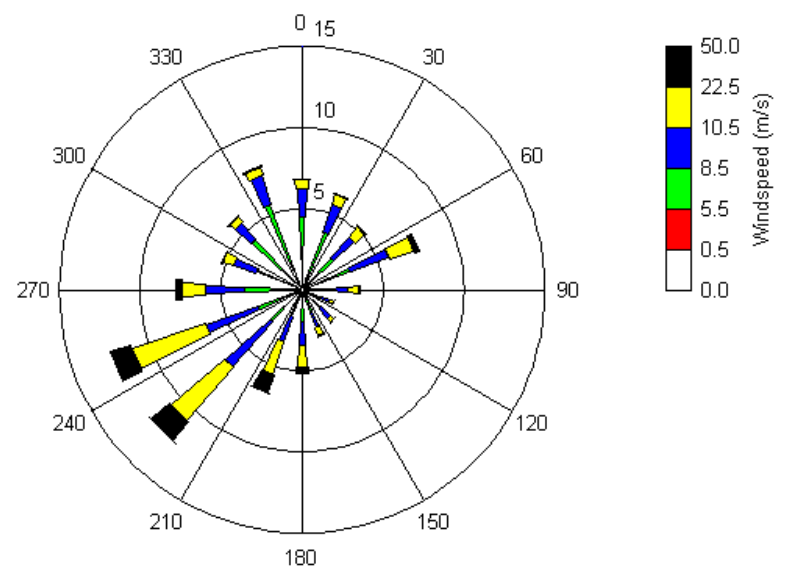

Figure 2. Wind rose plot for Boscombe.

\section{MULTIPURPOSE REEF DESIGN}

The final reef design incorporated the following main features; a dual level reef with a focus section (Mead and Black, 2001a, b) designed to draw maximum wave energy onto the reef and a wedge section (Mead and Black, 2001a, b) along the crest to break waves in a manner suitable for high-quality surfing. The design has a crest height of $0.5 \mathrm{~m}$ above chart datum. The reef produces a predominant 
right hand surfing ride approximately $70 \mathrm{~m}$ long with a shorter $30 \mathrm{~m}$ long left hand break. The white water generated after breaking on the left-handed wave dampens short-period chop originating from the south west quadrant so that it does not propagate through to the main right-handed wave. This design was set in water depths of 3-5 m (CD) (Figure 3 a).
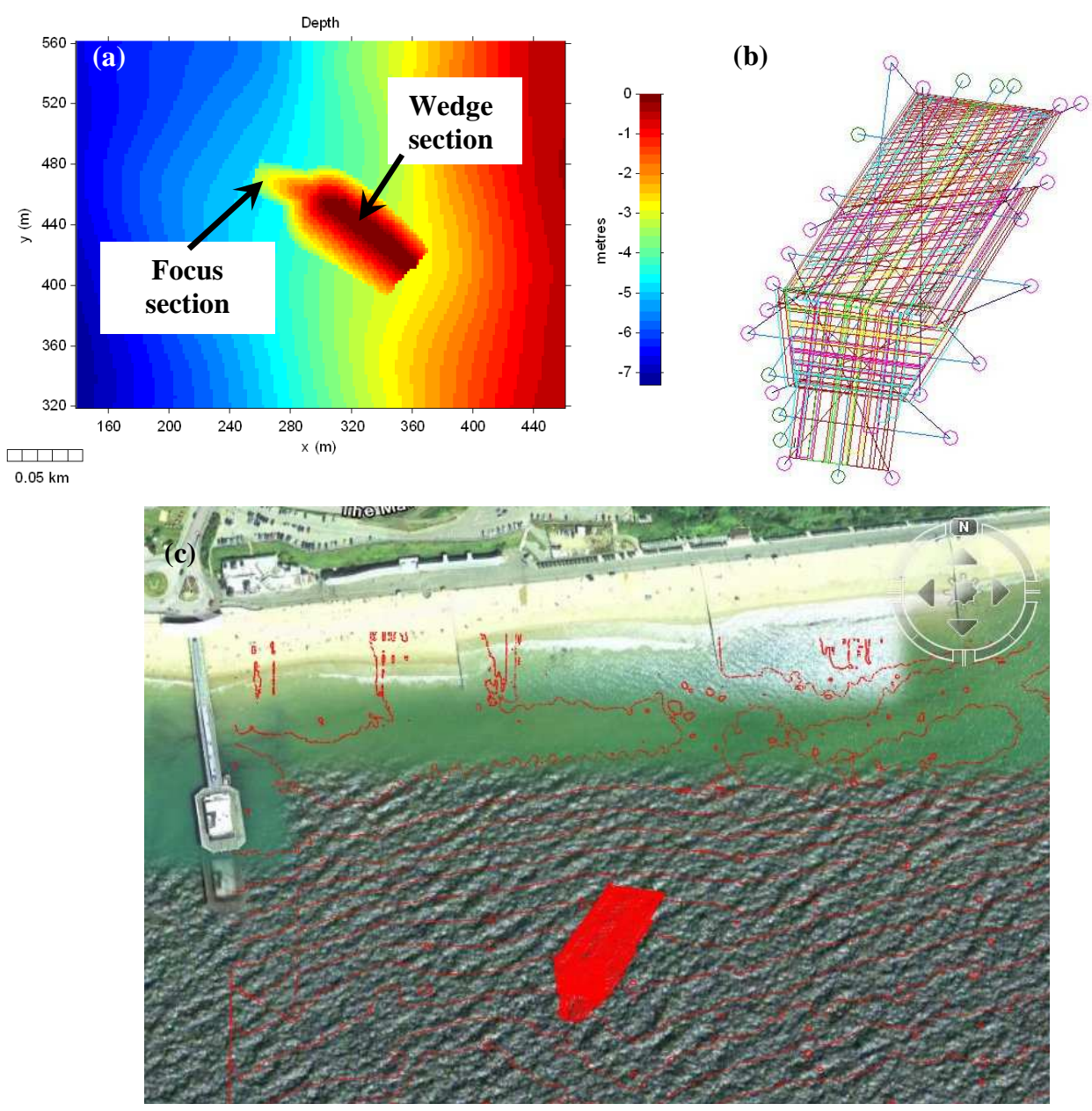

Figure 3 (a) Computer generated, numerical model design shape of the Boscombe Multipurpose Reef, (b) a schematic of the geotextile container layout and section anchoring strategy for the full scale prototype and (c) location of reef $\mathbf{2 8 0} \mathrm{m}$ offshore and east of Boscombe Pier, Poole Bay, England.

The design peel angle for wave breaking over the reef was optimized to cater to surfers with skill levels of 3-6 (intermediate to competent surfers, Hutt et al., 2001). In the present case, considering that surfable wave heights generally occurring at Bournemouth are on the order of 0.5 to $1.2 \mathrm{~m}$, peel angles of 50 to 70 degrees would be appropriate (Figure 4).

The reef design was further optimised through physical laboratory scale modelling. For these studies a model of the reef at 1:30 scale was built using scaled construction elements representing the sand filled geotextile containers to be used to construct the reef in reality. With this method the reef shape could be fine-tuned and the container layout specified prior to construction. Validation based on qualitative assessments of the wave breaking on the completed reef indicates that the laboratory modelling was reasonably accurate (Figure 5).

Further design/impact modelling was undertaken for environmental impact assessment and permitting purposes, which is not presented here. 


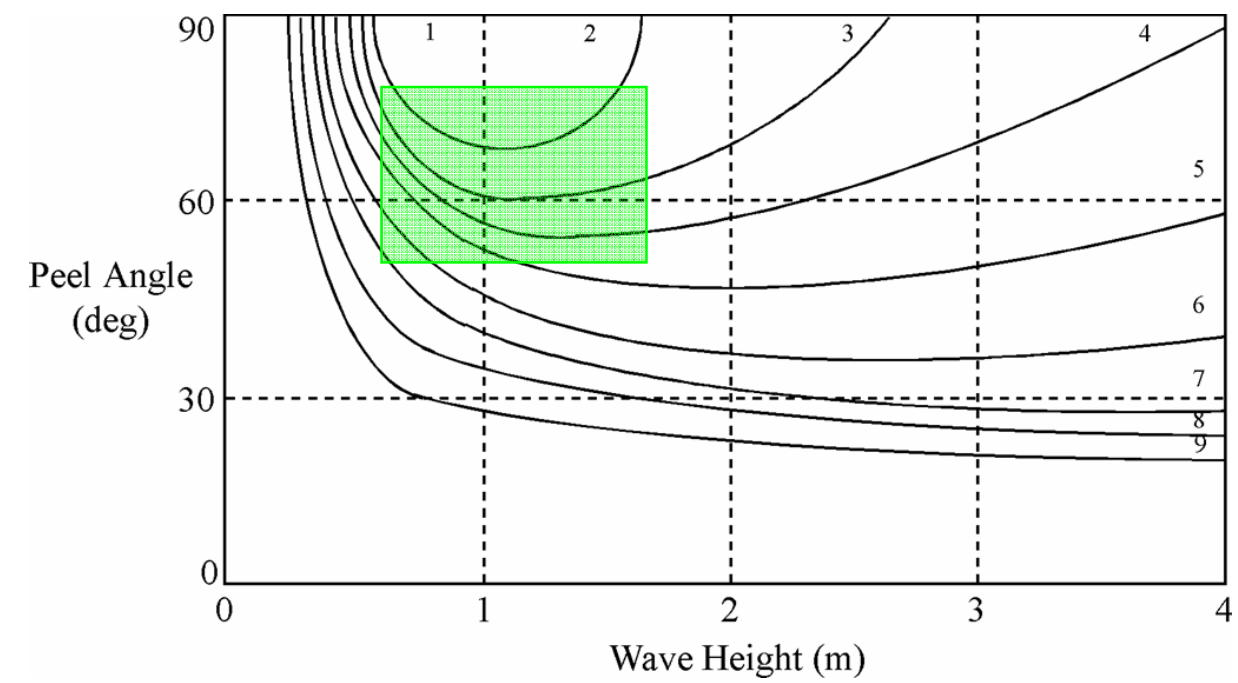

Figure 4. Design range of peel angle and wave height using the method og Hutt et al., 2001 for the Boscombe Reef
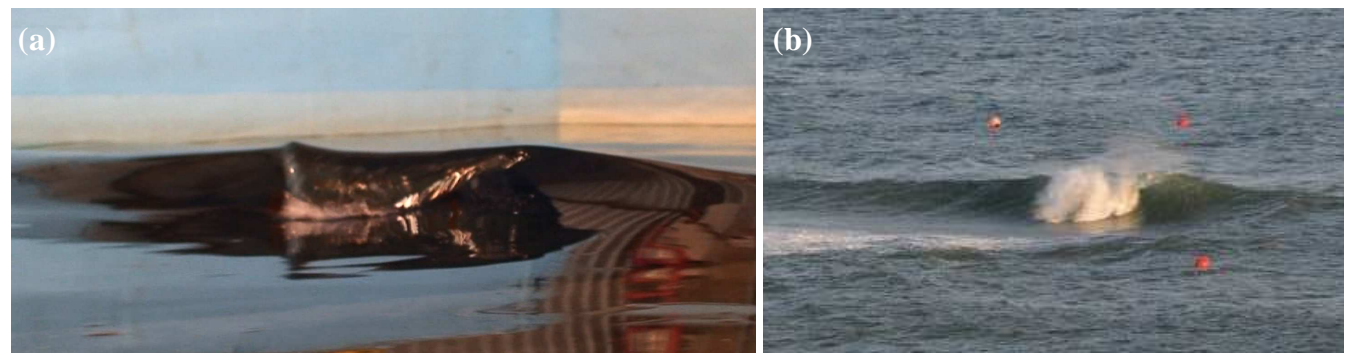

Figure 5. (a) Wave breaking over a 1:30 scale laboratory model of the Boscombe Reef and (b) a wave breaking over the nearly completed reef.

\section{REEF CONSTRUCTION}

Reef construction began in the summer of 2008. Construction was based on using large sand filled geotextile containers arranged in sections. The sections were compromised of up to 14 individual containers ranging in size from 15 to $40 \mathrm{~m}$ long with diameters on the order of 1 to $4 \mathrm{~m}$. Each section was deployed from a barge and anchored to the sea bed with 5 ton concrete blocks. The containers were filled through the use of a land-based pumping system connected to the reef via a $200 \mathrm{~m}$ long pipeline. Clean sand stocked-piled on the beach was pumped out to the reef in a sand/water slurry and the filling was controlled by divers (Figure 6 a,b).

This methodology of deploying sections of containers was employed for the lower layer of containers, however due to the large number of longer $(70 \mathrm{~m})$ containers in the main upper section, single container deployment was undertaken to reduce risk. If inclement whether set in and containers were left unfilled, there was a risk of containers shifting from their design location. Indeed, weather was a factor during the first construction season and in conjunction to a late start on the project, only the first layer of the reef was able to be finished. Once winter set in, construction was suspended until the following summer. During the second construction season in the summer 2009, each container was folded on to a floating raft, hitched into position and anchored to the lower layer by divers before filling. This method was effective and efficient and allowed the reef to be completed before the end of the construction window in September 2009 (Figure 7). 


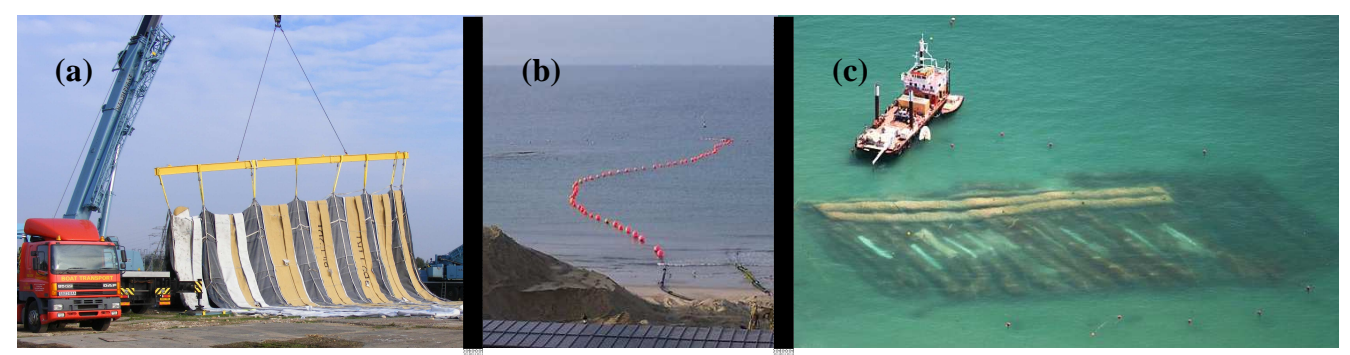

Figure 6. (a) Hoisting a section of unfilled geotextile containers on to the barge for deployment (b) the sand slurry pipeline (c) the completed lower layer with two of the top layer containers in place.

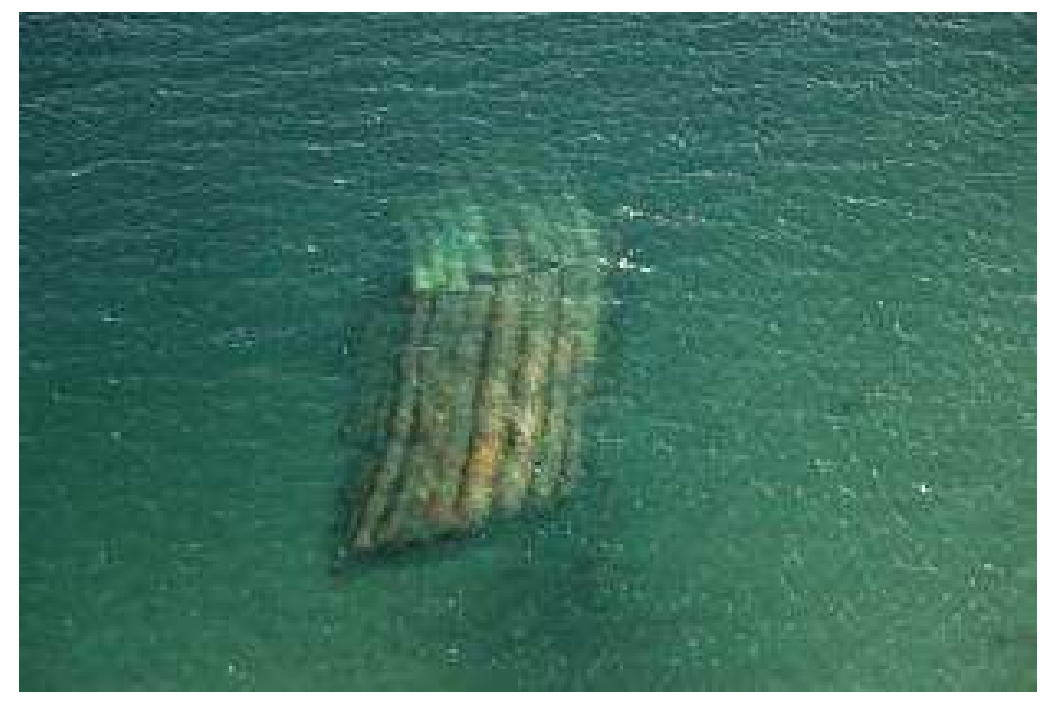

Figure 7. Aerial view of the Boscombe Reef September 2009.

\section{POST CONSTRUCTION MONITORING}

Since construction, the reef has been independently monitored for surfing performance, with a preliminary monitoring report delivered in March, 2010. This report judged the reef on 5 performance criteria including ride length, wave quality, wave height amplification, wave intensity and consistency. It should be noted that a baseline study of surfing conditions at Boscombe suggested that acceptable surfing conditions (prompting at least 5 surfers to enter the water and attempt to surf) occurred at Boscombe only $20 \%$ of the time (Davidson, 2009). It should also be noted, that at the exact reef location (200 $\mathrm{m}$ offshore) surfing conditions occurred $0 \%$ of the time, thus, even 1 day of surfing is an improvement over pre-reef conditions. The interim monitoring report found that the reef had achieved 4 out of 5 of the performance criteria, with ride length on the right hander being sometimes effected during longer period and lower tide conditions, when waves can be very fast and sometimes break with a collapsing form after take-off (although it is noted that the longer period wave conditions are outside the design wave specifications). 3 small containers will be added to the lower part of the reef in the location where the focus meets the wedge on the offshore side of the reef to influence the shoaling/breaking of longer period waves and increase ride length.

\section{Surfing}

In terms of surfing, under design conditions $\left(H_{10}=1 \mathrm{~m} \pm 0.5 \mathrm{~m} ; T=7 \mathrm{~s} \pm 2 \mathrm{~s}\right.$, and wave direction coming from $191^{\circ} \mathrm{N} \pm 6^{\circ}$ ), the reef has produced high-quality breaking waves suitable for stand up surfing, as per the design. When conditions are outside of the specified design range, the reef still produces rideable waves, however these are frequently more suitable to body-boarding due to the intense plunging nature of the wave breaking induced by the reef (see Figure 8 and supplemental material for a range of surfing and body boarding photos from the Boscombe Reef). Since the reef was 
completed in the late summer of 2009, it was able to be utilized in the Autumn and early Winter months of September through December. Indeed, this season is known to be the best time of year for surfing along the South Coast of England and this was also reported in the baseline study of surfing conditions (Davidson, 2009).

Based on an analysis of the wave climate at Boscombe, it was determined that the appropriate conditions for surfing existed on 20 different occasions between September 2009 and March 2010 (the period covering the preliminary assessment of surfability). The breakdown of good surfing conditions, marginal surfing conditions and poor surfing conditions are detailed in supplemental material 2 . It should also be noted that the winter of 2009 - 2010 was one of the coldest and snowiest on record for England, and this undoubtedly had an effect on the number of surfing participants willing to enter the water at Boscombe. As this report goes to press, the Boscombe reef will enter its second year of service.

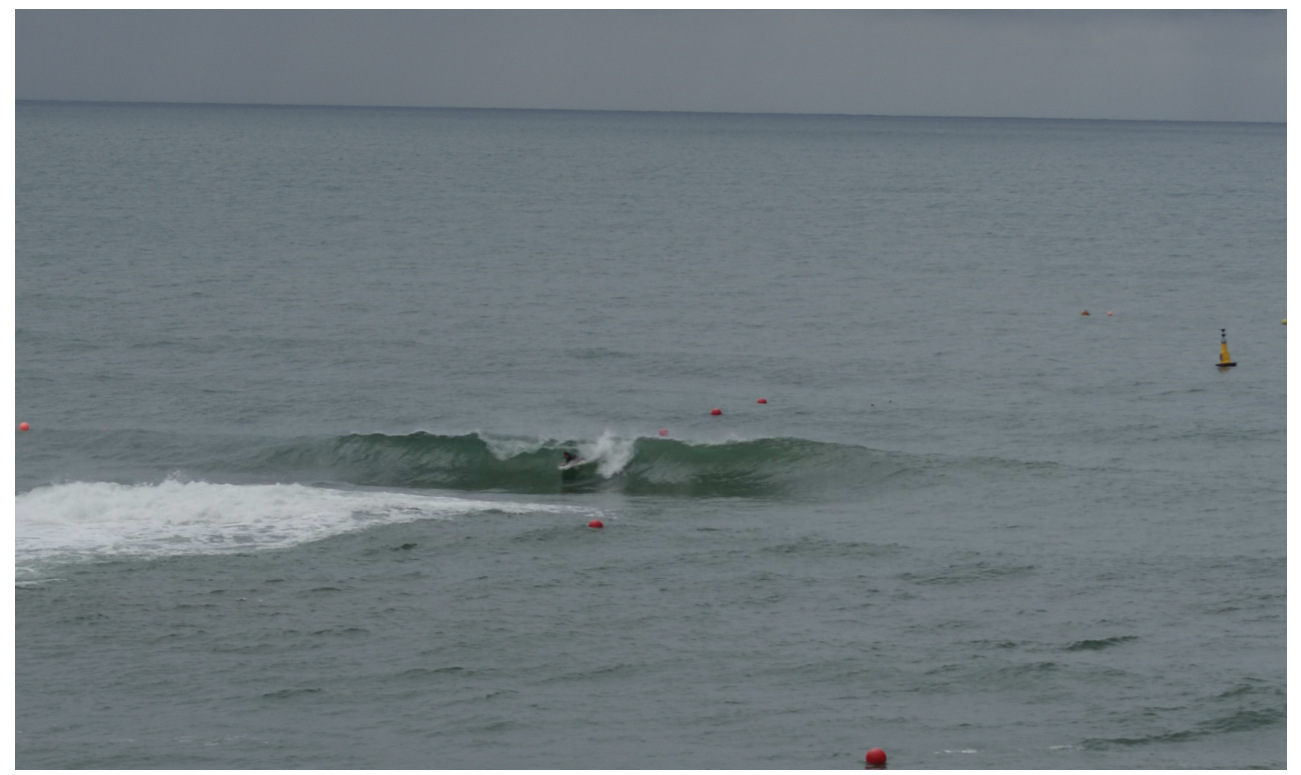

Figure 8. A body boarder surfing on the completed Boscombe Reef. Additional photos are provided in the suppemental material.

\section{Shoreline Response}

Since June 2008 (pre-construction) ASR has commissioned 17 bathymetry surveys and 3 beach profile surveys (the latter have coincided with the time/date of a bathymetry survey). Seven of the surveys are post-completion of the reef, and although intensive calibrated numerical modelling of morphological processes has been undertaken, here we are present a brief time-series view of the beach response with the combined bathymetry and beach profile surveys.

While net sediment transport is west to east due to the prevailing SW wind conditions, the short period of the waves means that initially cross-shore (offshore) sediment transport occurs. This crossshore transport renders the groynes along the length of Poole Bay (some 60 groynes along $19 \mathrm{~km}$ of beach) ineffective, especially when the compartments are full following renourishment, which occurs every 10-12 years or so. Internationally, detached or submerged breakwaters have been used typically along coastlines with small tidal fluctuations to control the cross-shore sand transport processes (e.g. Nielsen, 2001). Thus, as was demonstrated in the design/impact modelling for the project, a significant salient has developed in the lee of the reef, and extends asymmetrically to the west due to the west-east transport of sediment. Figure 9 presents overlays of the bathymetry and beach surveys from October 2009, January 2010 and March 2010 that show the development of the salient, and Figure 10 shows the salient response to the presence of the Boscombe Reef from the air.

This beach response to the Boscombe Reef provides support that detached and submerged reefs or breakwaters would be a useful option for retention of renourishment material in Poole Bay in the future. 


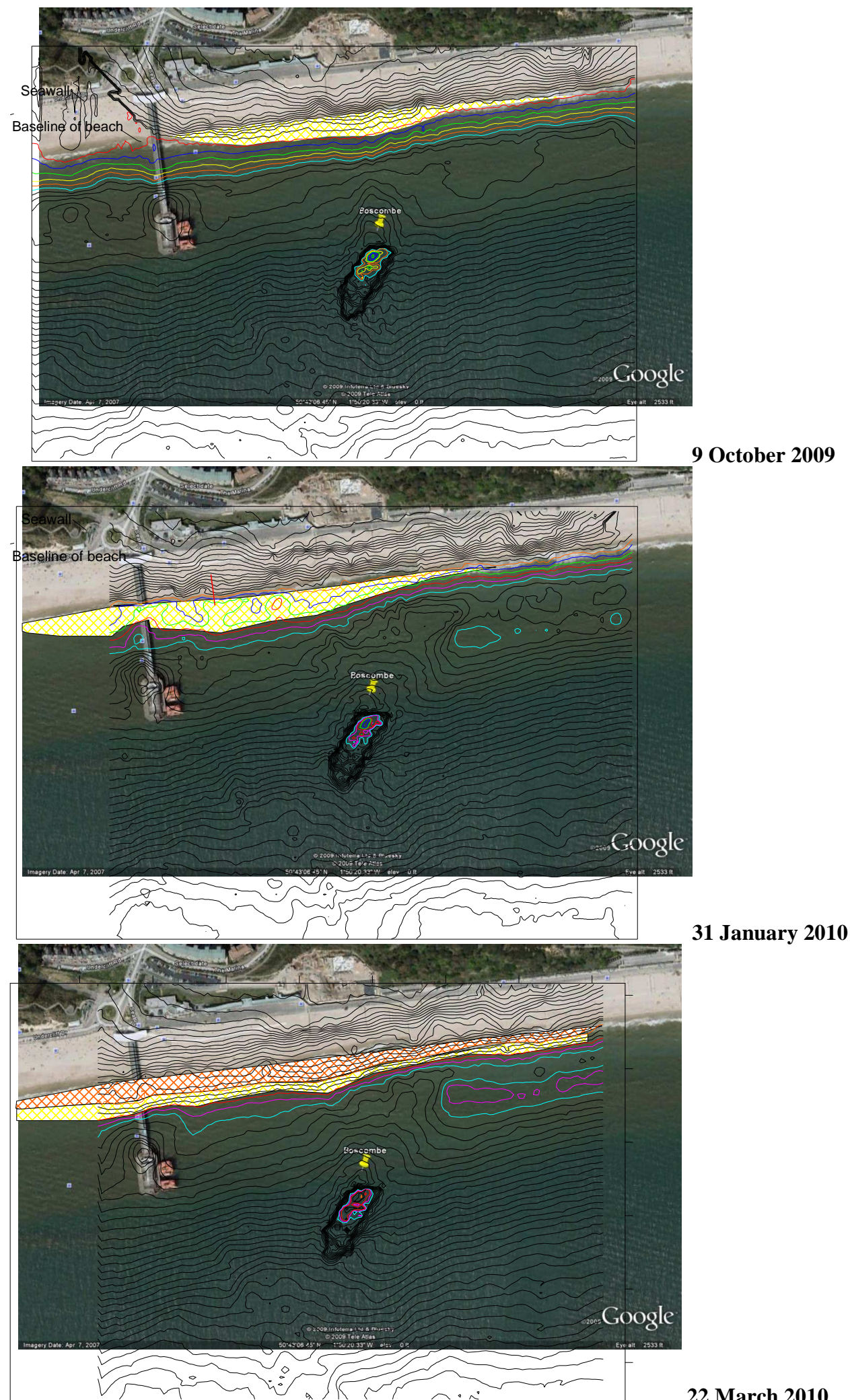

Figure 9. Time-series bathymetry and beach profile surveys indicating the development of the salient in response to Boscombe Reef. 


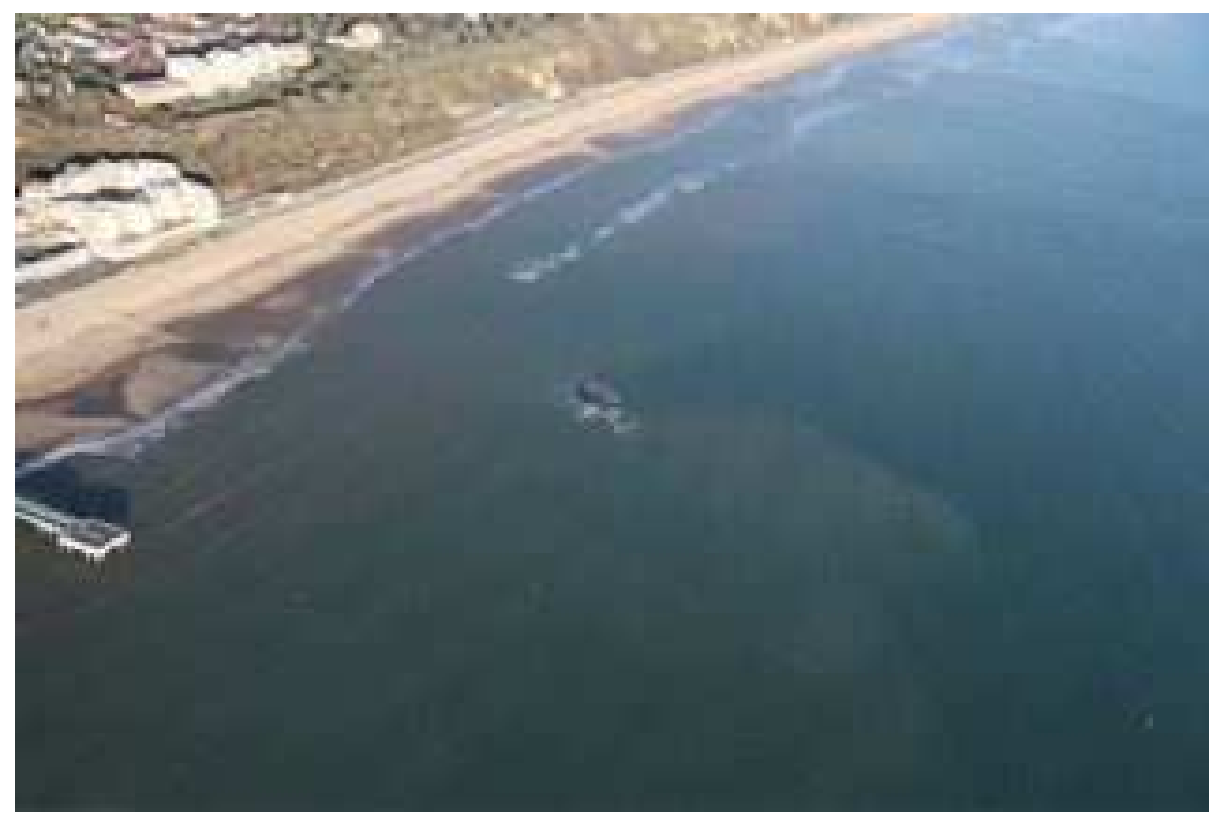

Figure 10. Aerial view of the beach response in the lee of Boscombe Reef (10 March 2010)

\section{Geotextile Container Stability}

The sand filled geotextile containers (SFC's) used in the construction of the reef are very large, with lengths of 15 to $40 \mathrm{~m}$ and diameters of 1 to $4 \mathrm{~m}$. As a result the individual construction units are quite massive and sufficiently stable under the typical and extreme wave loads experienced at Boscombe. No indication of container failures has been observed thus far art Boscombe and we remain confident that the reef structure is stable. In terms of settlement and scour, the reef has settled somewhat, reducing the overall crest height. However the magnitude of the settlement, determined from the post construction bathymetric surveys, is $0.5 \mathrm{~m}$ or less, as specified in the design.

\section{SUMMARY AND CONCLUSIONS}

Boscombe Reef was designed for the local conditions in Poole Bay to create a surfing break as a focus for the Boscombe Spa development on England's southern coast. The reef is comprised of 2 main sections, a Focus to increase wave height and define the take-off zone, and a Wedge to peel the waves down as they break in a way and at a rate conducive with surfing. The reef provides primarily a righthand break ( $\sim 70 \mathrm{~m}$ long) due to the prevailing wind from the southwest, with a shorter lefthand break ( $\sim 30 \mathrm{~m}$ long) that also helps to reduce the surface chop that is common of the local sea conditions.

Construction of the reef was undertaken with 54 sand-filled geotextile containers varying in length from $15 \mathrm{~m}$ to $70 \mathrm{~m}$, and with diameters of up to $4 \mathrm{~m}$. The containers were filled with sand from a beach-based slurry pump set-up, with divers placing the containers in predetermined locations in a twolayer configuration and monitoring the filling process. The large size of these sand-filled geotextile containers results in a very stable structure, following the expected initial settlement of up to $0.5 \mathrm{~m}$.

The reef has consistently produced surfing waves to the design specifications, especially under design wave conditions $\left(H_{10}=1 \mathrm{~m} \pm 0.5 \mathrm{~m} ; T=7 \mathrm{~s} \pm 2 \mathrm{~s}\right.$, and wave direction coming from $\left.191^{\circ} \mathrm{N} \pm 6^{\circ}\right)$, and has worked well in the capacity of a focus to compliment the Boscombe Spa development.

Monitoring of the beach response has recorded the development of a large salient in the lee of the reef. This salient is asymmetrical, with the location being more west of the reef position offshore, which is a consequence of the predominant west to east sediment transport direction. This beach response to the Boscombe Reef provides support that detached and submerged reefs or breakwaters would be a useful option for retention of renourishment material in Poole Bay in the future. 


\section{ACKNOWLEDGMENTS}

The authors would like to acknowledge Edward Aitken for his diligent bathymetry and beach surveying, the Bournemouth Borough Council for their forward thinking and development of awardwinning Boscombe Spa development, and the surfers and bodyboarders of Boscombe who have maintained support with regards to the Boscombe Multipurpose Reef.

\section{REFERENCES}

Davidson, M. 2009. A baseline Study of Surfing Conditions in the Boscombe Region and an investigation of Potential Improvements Due to the Installation of an Artificial Surfing Reef. University of Plymouth, Technical Report BDC052009-002.

Hutt, J.; Black, K. and Mead, S., 2001. Classification of Surf Breaks in Relation to Surfing Skill. Special Issue 29, Journal of Coastal Research p66-81.

Mead, S. T. \& K. P. Black, 2001a. Field Studies Leading to the Bathymetric Classification of WorldClass Surfing Breaks. Special Issue 29 of the Journal of Coastal Research on Surfing p5-20.

Mead, S. T. \& K. P. Black, 2001b. Functional Component Combinations Controlling Surfing Wave Quality at World-Class Surfing Breaks. Special Issue 29 of the Journal of Coastal Research on Surfing p21-32.

Nielsen, L, 2001. Newcastle Coastal Zone Management Plan: Coastal Engineering Advice. Technical report for Umwelt (Australia) Pty Ltd, March 2001. 